\title{
PANDEMIA ENTRE MUROS: O CUIDADO ÀS PESSOAS PRIVADAS DE LIBERDADE NO CONTEXTO DO NOVO CORONAVÍRUS
}

\author{
H. C. P. DE SIQUEIRA ${ }^{1}$, H. F. CARNEIRO ${ }^{2}$ \\ Universidade de Pernambuco \\ ORCID ID: $\underline{\text { http://orcid.org/0000-0001-5475-5079 }}^{1}$ \\ hanna.siqueira@gmail.com $^{1}$
}

Submetido 29/07/2020 - Aceito 20/01/2021

DOI: 10.15628/holos.2020.10853

\section{RESUMO}

O Brasil tem 748.009 pessoas cumprindo pena em todos os regimes. Quanto ao regime fechado, 362.547 são privadas de liberdade, ficando sob custódia do Estado. Os privados de liberdade ficam sob o cuidado das equipes de Atenção Básica da Unidade Prisional. O presente trabalho tem como objetivo iniciar discussão sobre os cuidados a saúde ofertados a essa determinada população. Realizamos uma revisão bibliográfica utilizando as bases de dados: SciELO, LILACS e Google Acadêmico. Em todos os estudos apresentados foram discutidas Leis e Decretos estaduais e nacionais com orientações para a prevenção da Covid-19 nos presídios do país. É inegável que existe a tentativa legal do cuidado. Cabe a toda sociedade refletir sobre o direito à saúde e a ausência deste em ambientes de grande aglomeração, como o sistema prisional brasileiro. As pessoas privadas de liberdade cometeram crime, perdendo seu direito à liberdade, porém não se pode negar o direito à humanidade e dignidade dessas pessoas.

PALAVRAS-CHAVE: Covid-19, prisões

\section{PANDEMIC BETWEEN WALLS: THE CARE OF PEOPLE DEPRIVED OF LIBERTY IN THE CONTEXT OF THE NEW CORONAVIRUS}

\begin{abstract}
Brazil has 748,009 people serving time in all regimes. As for the closed regime, 362,547 are deprived of liberty, being in state custody. Those deprived of liberty are under the care of the Primary Care Teams of the Prison Unit. The presente study aims to discuss the health care that has been offered to this particular population. We conducted a bibliographic review using the databases: SCiELO, LILACS and Google Scholar. In all the studies presented, state and national laws and decrees were
\end{abstract}

discussed with guidelines for the prevention of Covid-19 in the country's prisons. It is undeniable that there is the legal attempt of "care". It is up to the whole society to reflect on the right to health and its absence in environments of great agglomeration, such as the Brazilian prison system. People deprived of liberty committed a crime, losing their right to freedom. However, the right to humanity and dignity of these people cannot be denied.

KEYWORDS: Covid-19, prisons 


\section{INTRODUÇÃO}

O acesso a ações e serviços de saúde é legalmente garantido pela Constituição Federal de 1988, pela Lei no 8.080 de $1990^{1}$ que regulamenta o Sistema Único de Saúde (SUS) e pela Lei no 8.142 de 1990 que dispõe sobre a participação da comunidade na gestão do SUS. Saúde é um direito inegável a toda e qualquer pessoa que habite em território nacional.

Conforme é citado no Artigo 196 da Constituição Federal de 1988: "Saúde é um direito de todos e dever do Estado, garantido mediante políticas sociais e econômicas que visem à redução do risco de doença e de outros agravos e ao acesso universal e igualitário às ações e serviços para sua promoção, proteção e recuperação" (Brasil, 1988).

A rede de saúde que compõe o SUS é regulamentada pelas Leis Orgânicas 8.080 e 8.142/1990. Ela deve disponibilizar assistência a todas as pessoas. Essa assistência deve ser isenta de discriminação, reconhecendo e respeitando as diferenças e necessidades pessoais de cada ser na sua individualidade.

Dentro das unidades prisionais os serviços de saúde pública sempre foram uma realidade distante. Em 2003, os Ministérios da Justiça e da Saúde instituíram o Plano Nacional de Saúde no Sistema Penitenciário (PNSSP) através da Portaria Interministerial no 1.777 de 09 de setembro de 2003, pois houve a percepção que a prestação de ações de saúde para as pessoas privadas de liberdade (PPL) era necessária. Sendo assim, o PNSSP previa a inclusão da população privada de liberdade no SUS, garantindo que o direito à cidadania se efetive na perspectiva dos direitos humanos (Brasil, 2004).

Onze anos após a instituição do PNSSP ele foi reformulado, passando a atender por Política Nacional de Atenção Integral a Saúde das Pessoas Privadas de Liberdade no Sistema Prisional (PNAISP). A PNAISP tem como objetivo a garantia do direito à saúde de todas as pessoas privadas de liberdade, dentre outros (Brasil, 2014). Ela passa a ser o instrumento que traz inúmeros benefícios à $\mathrm{PPL}$, melhorando as ações de saúde que visem a promoção, prevenção e recuperação de saúde.

Citamos aqui algumas de suas diretrizes com o objetivo de iniciar a discussão a que se propõe este trabalho: atenção integral resolutiva, contínua e de qualidade às necessidades de saúde da PPL no sistema prisional, com ênfase em atividades preventivas, sem prejuízo dos serviços assistenciais; controle e/ou redução dos agravos mais frequentes que acometem a população privada de liberdade no sistema prisional; respeito à diversidade étnico-racial, às limitações e às necessidades físicas e mentais especiais, às condições econômico sociais, às práticas e concepções culturais e religiosas, ao gênero, à orientação sexual e à identidade de gênero (Brasil, 2014).

1 Lei que dispõe sobre as condições para a promoção, proteção e recuperação da saúde, a organização e o funcionamento dos serviços. 
Segundo dados do último sistema de Informações Estatísticas do Sistema Penitenciário Brasileiro (Infopen, 2019), o Brasil tem 748.009 mil pessoas cumprindo pena em todos os regimes. Quanto ao regime fechado, 362.547 mil são privadas de liberdade, ficando sob custódia do Estado. As pessoas que cumprem o regime aberto devem obter assistência à saúde nas unidades que compõe a Rede de Atenção à Saúde (RAS). Quanto às privadas de liberdade (em regime fechado), ficam sob o cuidado das equipes de Atenção Básica da Unidade Prisional.

Em 31 de dezembro de 2019, a Organização Mundial da Saúde (OMS) foi alertada sobre vários casos de pneumonia na cidade de Wuhan, província de Hubei, na República Popular da China. Tratava-se de uma nova cepa - tipo - de coronavírus que não havia sido identificada antes em seres humanos. Em 11 de março de 2020, a Covid-19 foi caracterizada pela OMS como uma pandemia. $O$ termo pandemia se refere à distribuição geográfica de uma doença e não à sua gravidade. A designação reconhece que, no momento, existem surtos de Covid-19 em vários países e regiões do mundo (Organização Pan-Americana de Saúde, 2020).

Levando em consideração tudo que foi discutido sobre saúde como direito e política de garantia à assistência das PPL, o presente trabalho tem como objetivo discutir sobre os cuidados a saúde que têm sido ofertados a essa determinada população. Trazemos o questionamento: quais medidas de cuidado, físico e mental, estão sendo tomadas para minimizar os impactos que a pandemia causada pelo novo coronavírus, a Covid-19, está causando nos privados de liberdade que fazem parte de um sistema prisional superlotado?

\section{DESENVOLVIMENTO}

\subsection{Superlotação prisional e saúde}

A superlotação é, talvez, o mais grave problema envolvendo o sistema penal hoje. As prisões encontram-se abarrotadas, não fornecendo a PPL um mínimo de dignidade. Todos os esforços feitos para a diminuição do problema não chegaram a nenhum resultado positivo, pois a disparidade entre a capacidade instalada e o número atual de PPL tem apenas piorado. Devido à superlotação, muitos dormem no chão de suas celas, às vezes no banheiro, próximos a buraco de esgoto. Nos estabelecimentos mais lotados, onde não existe nem lugar no chão, privados de liberdade dormem amarrados às grades das celas ou pendurados em rede. Os estabelecimentos penitenciários brasileiros variam quanto ao tamanho, forma e desenho. O problema é que, assim como nos estabelecimentos penais ou em celas de cadeias, o número de detentos que ocupam seus lugares chega a ser cinco vezes maior que sua capacidade (Camargo, 2006).

A população carcerária cresce muito e poucos presídios são construídos para amenizar essa situação. Infelizmente isso reflete diretamente nas rebeliões e fugas dos privados de liberdade. Estes, não possuindo um mínimo de condições de sobrevivência nas prisões, procuram fugir, tornando a superlotação carcerária um fator de risco não apenas para os privados de liberdade que cumprem suas penas em situações degradantes, como também para os funcionários encarregados de sua vigilância (Rosa, Tonial, Wendramin, 2020). 
Em relação à saúde da PPL, dispõe a Lei de Execuções Penais no 7.210 de 1984, em seu artigo 14, que "a assistência à saúde do preso e do internado, de caráter preventivo e curativo, compreenderá atendimento médico, farmacêutico e odontológico". Não obstante ao previsto em Lei, a situação real da saúde nos presídios é precária. Devido à insalubridade do ambiente, ao intenso uso de drogas e à falta de assistência médica e psicológica preventiva, o que se vê são pessoas dotados de uma saúde débil, incapaz de lhes propiciar condições satisfatórias de vida. A maioria se encontra com algum tipo de doença, sendo as principais aquelas que atingem o sistema respiratório, como a tuberculose, e as infecções sexualmente transmissíveis (Ferreira, 2012).

O Estado encontra dificuldades em assegurar a todos os privados de liberdade os devidos cuidados e higienização diante da Covid-19 que o Ministério da Saúde impõe e orienta a todos, para assim evitar que o vírus se prolifere tanto na sociedade quanto nesses ambientes. $O$ contato e a aglomeração de pessoas estão muito presentes, não havendo o distanciamento necessário entre os detentos e diante dessas condições de superlotação, piora a situação (Rosa, Tonial, Wendramin, 2020).

\subsection{Covid-19 e penitenciária}

No Brasil, em 20 de março de 2020, a transmissão do novo coronavírus passou a ser considerada comunitária, em todo o território nacional. A infecção causada pela Covid-19 pode cursar com quadros clínicos semelhantes à síndrome gripal, os quais podem se agravar para Síndrome Respiratória Aguda Grave (SRAG) ${ }^{2}$. Conquanto, a infecção pode ter início no trato respiratório superior, mas pode se disseminar e apresentar manifestações multissistêmicas, associadas ao risco alto de mortes e à possibilidade de sequelas (São Paulo, 2020).

As prisões apresentam precariedade nas instalações: são lugares sem ventilação, insalubres, muitas vezes destituídos de serviço de esgoto, acesso à água ou à alimentação adequada. Além das restrições sanitárias e arquitetônicas, a superpopulação inviabiliza a determinação de distanciamento social. Elas já eram locais de promoção de contágio altíssimo de doenças infecciosas (Faustino et. al., 2020).

Os impactos da pandemia intramuros vêm demandando um redirecionamento da atenção e da assistência a todos que ali vivem e que circulam pelas unidades e serviços que compõem os sistemas prisional e socioeducativo. Demonstrando ser uma questão dramática e desafiadora nas sociedades ao redor do globo, por causar o adoecimento de milhões e a morte de milhares de pessoas, a pandemia da Covid-19 apresenta particularidades quando se trata de espaços de privação de liberdade (Sanchéz et. al., 2020).

$\mathrm{Na}$ população livre, estima-se que cada infectado contamine 2 a 3 pessoas. Dadas as condições de encarceramento nas prisões brasileiras, pode-se estimar que um caso contamine até 10 pessoas. Assim, em uma cela com 150 PPL, 67\% deles estarão infectados ao final de 14 dias, e a totalidade, em 21 dias. A maioria dos infectados, 80\%, permanecerá assintomática ou desenvolverá

\footnotetext{
${ }^{2}$ Doença infecciosa de início súbito. Apresenta-se com sintomatologia semelhante à de um quadro gripal, porém, mais grave.
} 
formas leves; $20 \%$ progredirão para formas mais graves que necessitarão de hospitalização, dos quais, $6 \%$ em Unidade de Tratamento Intensivo (Sanchéz et. al., 2020).

A Comissão Internacional de Direitos Humanos (CIDH) divulgou, em 31 de março de 2020, nota em que expressa preocupação com a população carcerária frente à pandemia, especialmente pelas condições precárias de saúde e higiene, além da superlotação, e ressaltou a necessidade de autoridades do país seguirem o disposto nos Princípios e Boas Práticas para a Proteção das Pessoas Privadas de Liberdade, que preveem a garantia dos valores da dignidade humana e dos direitos e liberdades fundamentais, reconhecendo o direito fundamental que tem todas as pessoas privadas de liberdade. Essas pessoas devem ser tratadas humanamente, respeitando e garantindo sua dignidade, sua vida, sua integridade física, psicológica e moral, reconhecendo sua particular condição de vulnerabilidade, principalmente para aquelas que compõem grupos vulneráveis, como pessoas idosas, diabéticas, hipertensas, imunossuprimidas, pacientes com câncer, com doenças autoimunes, insuficiência cardíaca e renal, entre outras (Faustino et. al., 2020).

\subsection{Ações de cuidado contra a Covid-19 nas penitenciárias}

A Portaria no 135 de 18 de março de 2020, assinada pelo então ministro Sérgio Moro, visou estabelecer padrões mínimos de conduta a serem adotados em âmbito prisional, visando a prevenção da disseminação do vírus. Dentre seus artigos, chama a atenção quanto à restrição, máxima, da entrada de visitantes nas unidades prisionais, incluindo advogados (Brasil, 2020). Muitos estados estavam com as visitas as PPL suspensas desde março deste ano.

As estratégias de prevenção contra a Covid-19 não podem ser limitadas à interdição de visitas, suspensão das transferências entre unidades e interrupção de atividades em grupo, como as esportivas, escolares, educativas e religiosas. É essencial um plano de contingência para as prisões que adeque e torne operacionais as medidas preconizadas para a população geral (Sanchéz, 2020).

A CIDH apresentou proposta para a prevenção do novo coronavírus nas penitenciárias: a) as recomendações do uso de máscaras e do isolamento social por meio de cortinas ou marcações no chão para a delimitação da distância mínima de dois metros entre presos; b) a manutenção da população em espaço fechado, com ventilação e suprimentos para a realização de etiqueta respiratória, c) a garantia de meios de higienização constante das mãos, com água e sabão e a redução do número de visitantes ou suspensão total deles. A administração prisional tem que identificar os/as custodiados/as com sinais e sintomas de gripe e que a equipe de saúde da unidade prisional deve averiguar e identificar os casos suspeitos. Para atender tal proposição, o Ministério da Justiça - MJ recomendou a flexibilização das regras de arquitetura prisional e a construção de contêineres, de maneira a aumentar de alguma maneira o número de vagas quando deveria reduzir a população prisional (Faustino et. al., 2020).

Já o Conselho Nacional de Justiça (CNJ) fez ampla recomendação aos magistrados que, no exercício de suas atribuições de fiscalização de estabelecimentos prisionais e unidades socioeducativas, zelem pela elaboração e implementação de um plano de contingências pelo Poder 
Executivo que preveja, minimamente, as seguintes medidas: I - realização de campanhas informativas acerca da Covid-19, ações de educação em saúde e medidas de prevenção e tratamento para agentes públicos, PPL, visitantes e todos os que necessitam adentrar nos estabelecimentos; II - procedimento de triagem pelas equipes de saúde nas entradas de unidades prisionais e socioeducativas, com vistas à identificação prévia de pessoas suspeitas de diagnóstico de Covid-19 e prevenção do contato com a população presa ou internada; III - adoção de medidas preventivas de higiene, tais como aumento da frequência de limpeza de todos os espaços de circulação e permanência das pessoas custodiadas e privadas de liberdade, com atenção especial para higienização de estruturas metálicas e algemas, instalação de dispensadores de álcool gel nas áreas de circulação, entre outros; IV - abastecimento de remédios e fornecimento obrigatório de alimentação e itens básicos de higiene pela Administração Pública e a ampliação do rol de itens permitidos e do quantitativo máximo de entrada autorizada de medicamentos, alimentos e materiais de limpeza e higiene fornecidos por familiares e visitantes; $V$ - fornecimento ininterrupto de água para as PPL e agentes públicos das unidades ou, na impossibilidade de fazê-lo, ampliação do fornecimento ao máximo da capacidade instalada; VI - adoção de providências para evitar o transporte compartilhado de PPL, garantindo-se manutenção de distância respiratória mínima e a salubridade do veículo; VII - designação de equipes médicas em todos os estabelecimentos penais ou socioeducativos para a realização de acolhimento, triagem, exames médicos, testes laboratoriais, coleta de amostras clínicas, vacinação, referenciamento para unidade de saúde de referência e outras medidas profiláticas ou tratamentos médicos específicos, observando-se o protocolo determinado pela autoridade sanitária; VIII - fornecimento de equipamentos de proteção individual para os agentes públicos da administração penitenciária e socioeducativa; e IX - planejamento preventivo para as hipóteses de agentes públicos com suspeita ou confirmação de diagnóstico de Covid-19, de modo a promover o seu afastamento e substituição, considerando-se a possibilidade de revisão de escalas e adoção de regime de plantão diferenciado (Brasil, 2020).

A testagem das pessoas privadas de liberdade, profissionais de segurança e de saúde com quadro gripal deveria ser considerada estratégia prioritária para o enfrentamento da pandemia nas prisões. Entretanto, as PPL não são consideradas como prioritárias para a testagem dos casos suspeitos e mesmo os que faleceram com suspeita de Covid-19 não foram testados post mortem (Sanchéz, 2020).

Nos parece que seguimos na contramão das recomendações universais de prevenção à Covid-19.

\section{METODOLOGIA}

Com o objetivo de alcançar o propósito desse trabalho, realizamos uma revisão literária fazendo coleta de produções através da Biblioteca Virtual em Saúde - BVS, sendo utilizadas as bases de dados: Scientific Electronic Library Online - SciELO; Literatura Latino-Americana e do Caribe em Ciências da Saúde - LILACS e Google Acadêmico. Foram pesquisados arquivos dentro do período de 
janeiro a junho de 2020. O método utilizado foi o dedutivo. Utilizou-se como mecanismos de coleta de dados as fontes bibliográficas, tais como artigos e materiais disponibilizados por meio eletrônico.

Para Gil (2008), a revisão bibliográfica é uma forma de pesquisa que emerge da necessidade de revistar conceitos, temas e pesquisas já apresentadas com a finalidade de contribuir para o desenvolvimento temático. Nessa forma de pesquisa, o pesquisador se propõe a organizar uma biblioteca de leitura que versam sobre o tema. A seleção dessa biblioteca se dá por escolhas metodológicas ou teóricas ou mesmo epistemológicas.

A revisão literária é baseada no pressuposto de que o conhecimento se acumula e que nós aprendemos e construímos sobre o que outros têm feito. A investigação científica é um esforço coletivo de muitos pesquisadores que partilham os seus resultados com outros e que buscam o conhecimento como uma comunidade (John, 2017).

A busca foi realizada utilizando-se as seguintes palavras-chave: Covid-19 e prisões, encontradas nos Descritores em Ciências da Saúde - DeCS e na Biblioteca Virtual em Saúde. Procuramos artigos que tivessem sido publicados entre janeiro e junho de 2020. Quanto aos critérios de inclusão, foram usados: textos completos disponibilizados online e artigos publicados na língua portuguesa, para que fosse possível aproximar o objetivo da pesquisa ao contexto atual.

\section{RESULTADOS E DISCUSSÃO}

Na base de dados SciELO não foi achada nenhuma publicação a respeito do novo coronavírus nas unidades prisionais entre janeiro e junho de 2020. Quando pesquisado na LILACS, foi achada apenas uma nota técnica com orientações quanto às medidas de enfrentamento à Covid-19 no sistema prisional de Santa Catarina, tendo como objetivo orientar padrões mínimos de conduta a serem adotados pelas equipes de Saúde do PNAISP no âmbito prisional, visando a prevenção da disseminação da Covid-19. A mesma foi publicada em março de 2020.

Quando a pesquisa foi feita na base de dados do Google Acadêmico, foram achados nove arquivos para ampla discussão nesse trabalho. Desses nove, cinco se caracterizaram como notas técnicas e informes. Tais arquivos não foram inclusos na amostra. Quanto aos quatro arquivos restantes, tratava-se de artigos publicados em periódicos conforme apresentado na tabela abaixo (Tabela 1).

Tabela 1: Informações contidas nos periódicos incluídos na revisão (Fonte: SciELO e Google Acadêmico).

\begin{tabular}{|c|c|c|c|c|c|c|}
\hline AUTOR & TÍTULO & PERIÓDICO & ANO & METODOLOGIA & OBJETIVO & \\
\hline $\begin{array}{l}\text { Tavares, } \\
\text { Garrido } \\
\text { Santoro }\end{array}$ & $\begin{array}{l}\text { Política de } \\
\text { saúde no } \\
\text { cárcere } \\
\text { fluminense: } \\
\text { impactos da } \\
\text { pandemia de } \\
\text { Covid-19 }\end{array}$ & $\begin{array}{l}\text { Revista } \\
\text { Estudos } \\
\text { Institucionais }\end{array}$ & 2020 & $\begin{array}{l}\text { Revisão } \\
\text { bibliográfica }\end{array}$ & $\begin{array}{l}\text { Analisar } \\
\text { gestão } \\
\text { saúde } \\
\text { ambiente } \\
\text { prisional. }\end{array}$ & $\begin{array}{l}\text { a } \\
\text { da } \\
\text { no }\end{array}$ \\
\hline
\end{tabular}

HOLOS, Ano 36, v.5, e10853, 2020 


\begin{tabular}{|c|c|c|c|c|c|}
\hline Lage & $\begin{array}{l}\text { O direito } \\
\text { fundamental } \\
\text { à saúde da } \\
\text { mulher } \\
\text { privativa de } \\
\text { liberdade em } \\
\text { tempos de } \\
\text { Covid-19 }\end{array}$ & $\begin{array}{ll}\text { Revista } \\
\text { Acadêmica de } \\
\text { Direito da } \\
\text { UNIGRANRIO }\end{array}$ & 2020 & $\begin{array}{l}\text { Revisão } \\
\text { bibliográfica }\end{array}$ & $\begin{array}{l}\text { Mostrar para a } \\
\text { sociedade que } \\
\text { essa parcela da } \\
\text { população } \\
\text { marginalizada } \\
\text { precisa ser } \\
\text { vista com um } \\
\text { olhar } \\
\text { diferente, } \\
\text { apresentando } \\
\text { diversas ações } \\
\text { relacionadas à } \\
\text { saúde } \\
\text { prestadas ao } \\
\text { sistema } \\
\text { penitenciário. }\end{array}$ \\
\hline $\begin{array}{l}\text { Rosa, Tonial e } \\
\text { Wendramin }\end{array}$ & $\begin{array}{l}\text { Sistema } \\
\text { penitenciário } \\
\text { catarinense, } \\
\text { superlotação } \\
\text { e o Covid-19: } \\
\text { como o STJC } \\
\text { está lidando } \\
\text { com a } \\
\text { situação }\end{array}$ & $\begin{array}{ll}\text { Anuário } & \\
\text { Pesquisa } & \text { e } \\
\text { Extensão } & \\
\text { UNOESC São } \\
\text { Miguel } \\
\text { Oeste }\end{array}$ & 2020 & $\begin{array}{l}\text { Revisão } \\
\text { bibliográfica }\end{array}$ & $\begin{array}{l}\text { Fazer uma } \\
\text { análise sobre a } \\
\text { atual situação } \\
\text { do sistema } \\
\text { penitenciário } \\
\text { brasileiro e os } \\
\text { meios de } \\
\text { enfrentamento } \\
\text { perante um } \\
\text { possível } \\
\text { cenário de } \\
\text { contaminação } \\
\text { pelo Covid-19. }\end{array}$ \\
\hline $\begin{array}{l}\text { Sanchéz, } \\
\text { Simas, Diuana } \\
\text { e Larouze }\end{array}$ & $\begin{array}{l}\text { COVID-19 } \\
\text { nas prisões: } \\
\text { um desafio } \\
\text { impossível } \\
\text { para a saúde } \\
\text { pública? }\end{array}$ & $\begin{array}{l}\text { Cadernos de } \\
\text { Saúde Pública }\end{array}$ & 2020 & Ensaio & $\begin{array}{l}\text { Avaliar } \\
\text { condições à } \\
\text { disseminação } \\
\text { do COVID-19 } \\
\text { nas prisões. }\end{array}$ \\
\hline
\end{tabular}

Em todos os estudos apresentados foram discutidas Leis e Decretos estaduais e nacionais com orientações para a prevenção da Covid-19 nos presídios do país. É inegável que existe a tentativa legal do cuidado, porém, como citado por Tavares et. al. (2020), em relação às medidas tomadas no Rio de Janeiro: "parece claro que a opção do Governador em relação às pessoas presas não tem nenhuma relação com a preservação da saúde dos detentos, porquanto promove um isolamento dos mesmo em relação ao resto da sociedade, ao passo que os detentos continuam 
amontoados em constante contato físico, incrementando o risco de contágio do vírus, contrariamente às medidas mundiais de enfrentamento da pandemia".

Sabemos que nas penitenciárias do Brasil temos um sistema superlotado e, como uma das consequências, as PPL sobrevivem com condições mínimas de saúde e higiene. Nas penitenciárias existe falta ou restrição à água, álcool e sabonete. Por vezes a alimentação, também, é precária. Torna-se difícil fazer valer o distanciamento social, a manutenção da saúde e a prevenção de agravos nesse contexto. Conforme citado por Assis (2007 como citado em Rosa et. al., 2020), " $a$ superlotação das celas, sua precariedade e sua insalubridade tornam as prisões num ambiente propício à proliferação de epidemias e ao contágio de doenças. Todos esses fatores estruturais aliados ainda à má alimentação, seu sedentarismo, o uso de drogas, a falta de higiene e toda a lugubridade da prisão, fazem com que um preso que adentrou lá numa condição sadia, de lá não saia sem ser acometido de uma doença ou com sua resistência física e saúde fragilizadas".

Alguns autores citam o cancelamento das visitas como algo não tão positivo, relacionado à questão psicológica dos privados de liberdade, que tantas vezes já se encontram em situação vulnerável quanto à sua saúde física e mental. Sanchéz et. al. (2020) dizem que "é um equívoco pensar que o bloqueio total das prisões e a limitação de informações sobre a situação das unidades prisionais não evitarão a disseminação da Covid-19".

Três dos textos citam como medidas importantes o cuidado com os profissionais que atuam diariamente nas unidades prisionais. O texto de Rosa et. al. (2020) cita recomendação para "a proteção da vida e da saúde das pessoas privadas de liberdade, dos magistrados, e de todos os servidores e agentes públicos que integram o sistema de justiça penal, prisional e socioeducativo, sobretudo daqueles que integram o grupo de risco".

Em todos os textos é discutido o direito à saúde como dever do Estado, como citado por Lage (2020) a respeito do direito à saúde enquanto política pública: "A mudança esperada não deve partir somente dos profissionais que lidam com os encarcerados, devendo ocorrer também uma conscientização da sociedade em que vivemos, de que tais políticas públicas e direitos não são regalias da população carcerária e que os direitos humanos devem ser respeitados, não devendo ser negado o direito à saúde a nenhum indivíduo, independente da sua condição ou do que venha a ter cometido".

\section{CONSIDERAÇÕES FINAIS}

Podemos perceber a ausência de discussões a respeito das medidas de prevenção e cuidados com as PPL no Brasil. A maioria dos documentos lançados no país não cita, ou cita de maneira superficial, essa população. Sabemos que as principais recomendações para a prevenção na população, a saber, o distanciamento social e práticas de higiene como a lavagem das mãos, são de difícil aplicação nas penitenciárias do Brasil. Muitas vezes essa população não dispõe de produtos básicos para higiene pessoal e nem de espaço físico para o desejável distanciamento social. Isso torna as unidades prisionais em ambientes propensos para a proliferação rápida de vírus e bactérias. 
Cabe a sociedade refletir sobre o seu direito à saúde e a ausência deste em ambientes de grande aglomeração, como o sistema prisional brasileiro. As PPL cometeram crimes, perdendo seu direito à liberdade. Porém, não se pode negar o direito à saúde, humanidade e dignidade dessas pessoas. Na Constituição Federal não se exclui nenhum cidadão do direito à saúde. É dever do Estado cuidar dessas pessoas que estão sob sua custódia, dar condições de moradia a estes que habitam sob o seu teto e, principalmente, condições físicas e psicológicas para que consigam enfrentar esse momento de pandemia. Pouco está sendo pensado para a qualidade de saúde mental das PPL nesse momento.

Pensar possibilidades de enfrentamento para a Covid-19 dentro das unidades prisionais, evidenciando a PNAISP e oferecendo condições de trabalho aos profissionais que atuam nas unidades prisionais é proposto como desafio ao Estado. Deve-se planejar estratégias para enfrentamento dos impactos físicos e mentais causados pela Covid-19 dentro das unidades prisionais, tornando esses espaços dignamente habitáveis para pessoas e não propagadores de doenças infecciosas.

\section{REFERÊNCIAS}

BRASIL. Constituição da República Federativa do Brasil. Brasília, 1988. Disponível em: <http://www.planalto.gov.br/ccivil_03/constituicao/constituicaocompilado.htm> Acesso em: 06 mai. 2020.

BRASIL. Ministério da Saúde. Plano Nacional de Saúde no Sistema Penitenciário. Brasília, 2004. Disponível em: <http://bvsms.saude.gov.br/bvs/publicacoes/cartilha_pnssp.pdf>. Acesso em: 06 de mai. 2020.

BRASIL. Ministério da Saúde e Ministério da Justiça. Política Nacional de Atenção Integral à Saúde das Pessoas Privadas de Liberdade no Sistema Prisional. Brasília, 2014. Disponível em: <http://bvsms.saude.gov.br/bvs/saudelegis/gm/2014/pri0001_02_01_2014.html>. Acesso em: 06 mai. 2020.

BRASIL. Ministério da Justiça e Segurança Pública. Departamento Penitenciário Nacional, 2019. Disponível em: <http://depen.gov.br/DEPEN/depen/sisdepen/infopen>. Acesso em: 06 mai. 2020.

BRASIL. Conselho Nacional de Justiça. Recomendação no 62, de 17 de março de 2020. Recomenda aos Tribunais e magistrados a adoção de medidas preventivas à propagação da infecção pelo novo coronavírus - Covid-19 no âmbito dos sistemas de justiça penal e socioeducativo. Disponível em: <https://www.cnj.jus.br/wp-content/uploads/2020/03/62Recomendação.pdf>. Acesso em: 02 jul. 2020.

CAMARGO, V. (2006, setembro) Realidade do Sistema Prisional no Brasil. In: Âmbito Jurídico, Rio Grande, IX, n. 33. Disponível em: <http://www.ambitojuridico.com.br/site/index.php?n_link=revista_artigos_leitura\&artigo_id=1299>. Acesso em 06 jun. 2020. 
FAUSTINO D.M., LEONARDI F.G., MATSUDA F.E., WAGNER G.A., HARADA J., FURTADO L.A.C., ...JUNQUEIRA, V. (2020) A atual crise sanitária e de saúde causada pelo avanço da COVID-19 e a situação da população carcerária. Repositório Institucional UNIFESP. Disponível em: < https://repositorio.unifesp.br/handle/11600/53369>. Acesso em: 07 jul. 2020.

FERREIRA P.G. (2012) A estrutura do sistema prisional brasileiro frente aos objetivos da teoria da pena. Revista Âmbito Jurídico. Disponível em: $<$ https://ambitojuridico.com.br/cadernos/direito-penal/a-estrutura-do-sistema-prisionalbrasileiro-frente-aos-objetivos-da-teoria-da-pena/> Acesso em: 07 jul. 2020.

GIL, A. C. (2008) Como elaborar projetos de pesquisa. 5a edição. São Paulo: Atlas.

JOHN, S. (2017) Métodos de Pesquisa. CreateSpace Independent Publishing Platform.

LAGE, V. C. C. (2020) O direito fundamental à saúde da mulher privativa de liberdade em tempos de Covid-19. Revista Acadêmica de Direito da UNIGRANRIO. Disponível em: <http://publicacoes.unigranrio.edu.br/index.php/rdugr/article/view/6322> Acesso em: 9 jul 2020.

ROSA A.M., TONIAL S.M., WENDRAMIN C. (2020) Sistema penitenciário catarinenses, superlotação e o Covid-19: como o TJSC está lidando com a situação. Anuário pesquisa e extensão Unoesc São Miguel do Oeste.

ORGANIZAÇÃO PAN-AMERICANA DE SAÚDE. (2020) Folha informativa - COVID-19 (doença causada pelo novo coronavírus). Disponível em: <https://www.paho.org/bra/index.php?option=com_content\&view=article\&id=6101:Covid19 \&ltemid=875> Acesso em: 06 maio 2020.

SANCHÉZ A., GARCIA A.M., ALMEIDA B.C., MELO B.D., PEREIRA D.R., JULIÃO E., ...DIUANA, V. (2020) Saúde mental e atenção psicossocial na pandemia COVID-19: COVID e a população privada de liberdade. Rio de Janeiro: Fiocruz/CEPEDES. Cartilha. 21p. Disponível em: < https://www.arca.fiocruz.br/handle/icict/41680> Acesso em: 01 jul. 2020.

SANCHÉZ A., SIMAS L., DIUANA V., LAROUZE B. (2020) COVID-19 nas prisões: um desafio impossível para a saúde pública? Caderno de Saúde Pública, v. 36, n. 5. Rio de Janeiro. Disponível em: <https://doi.org/10.1590/0102-311x00083520>. Acesso em: 07 jul. 2020.

SÃO PAULO. Governo Estadual de São Paulo. (2020) Doença pelo novo Coronavírus (COVID-19) diretrizes e orientações para os surtos em unidades prisionais. Centro de Vigilância Epidemiológica Prof. Alexandre Vranjac/CCD/SES-SP. Disponível em: $<$ http://docs.bvsalud.org/biblioref/2020/06/1097762/orientacoes_surtos_unidades_prisionai s010620.pdf>. Acesso em: 06 de jul. de 2020.

TAVARES, N. L. F.; GARRIDO, R. G.; SANTORO, A. E. R. (2020, abril) Política de saúde no cárcere fluminense: impactos da pandemia de Covid-19. REI - Revista Estudos Institucionais, [S.I.], v. 6,
n.
$1, \quad$ p.
277-300.
ISSN
2447-5467.
Disponível
em: 
<https://www.estudosinstitucionais.com/REl/article/view/480>. Acesso em: 17 jul. 2020. doi:https://doi.org/10.21783/rei.v6i1.480.

\section{COMO CITAR ESTE ARTIGO:}

Siqueira, H. C. P. de, Carneiro, H. F. (2020). Pandemia entre muros: o cuidado às pessoas privadas de liberdade no contexto do novo Coronavírus. Holos. 36(5), 1-13.

\section{SOBRE OS AUTORES}

\section{H. C. P. DE SIQUEIRA}

Possui bacharelado em Enfermagem pela Escola Superior de Saúde de Arcoverde (2011.1). Atuou durante 11 (onze) meses como enfermeira plantonista na Unidade Mista Santa Clara no município de Tupanatinga - PE. Participou do Programa de Valorização da Atenção Básica (PROVAB) em 2012, atuando na Atenção Básica do município de Arcoverde - PE. Tem experiência como docente, ministrando diversos cursos profissionalizantes na área de saúde do Serviço Nacional de Aprendizagem Comercial (SENAC) e cursos técnicos de enfermagem pelo Centro de Ensino Técnico de Arcoverde (CETA). Desempenhou função de enfermeira auditora (20132016) e enfermeira plantonista (2015-2019) na Maternidade Alcides Cursino (APAMIB). Atuou como Apoiadora Institucional das Equipes de Atenção Prisional no Presídio de Santa Cruz do Capibaribe (PSCC) de 2016 a 2018. Em meados de 2018, iniciou jornada profissional atuando no projeto Prevenção para Tod@s que é uma parceria da Secretaria de Saúde do Estado de Pernambuco com a Organização das Nações Unidas para a Educação, a Ciência e a Cultura (UNESCO). É especialista em Saúde Pública (UPE), Saúde da Família pela Universidade do Maranhão (UFMA) e em Obstetrícia pelo Centro de Formação e Aperfeiçoamento Profissional (CEFAPP). Atualmente faz mestrado profissional em Saúde Mental pela Universidade de Pernambuco (UPE) e cursa especialização em Docência em Enfermagem pela Faculdade de Ciências da Bahia (FACIBA). E-mail: hanna.siqueira@gmail.com

ORCID ID: http://orcid.org/0000-0001-5475-5079

\section{H. F. CARNEIRO}

Graduação Psicologia: Universidade Federal do Ceará (1985). Mestrado Ciencias de La Religión - Universidad Pontificia Comillas Madrid (1995). Doutorado em Psicologia - Fundamentos y Desarrollos Psicoanalíticos: Universidad Pontificia Comillas Madrid (1997). Estágio Sênior (pos-doc): CNRS - CERMES3/ CESAMES Université Paris V - Sorbonne (2010-2011). Professor Titular da Universidade de Fortaleza - UNIFOR período 1987-2012. Professor Associado e Livre docente UPE 2018-Atual.Coordenador Setorial de Graduação 05/2013 a 02/2016. Vice-diretor da UPE-Garanhuns 03 a 08/2016. Diretor UPE-Garanhuns/ Multicampi 09/2016-01/2017. Coordenador Mestrado Saúde Mental UPE-Garanhuns. Experiência com ênfase em Intervenção Terapêutica. Atuação: psicanálise, dietética, subjetividade, mal-estar, laço social, violência, saúde mental e aspectos subjetivos do Mal e Alzheimer. Pesquisador da ANPEPP - GT. Redes de psicanálise teorias e práticas (2015-atual). Membro fundador da AUPPF. Editor da Revista Mal-estar e Subjetividade (2000-2011). Pesquisador PQ2 CNPq 2006-2019. Autor dos livros: AIDS A nova desrazão da humanidade (Ed. Escuta, 2000), Que Narciso é esse? (Livro eletrônico CNPq, 2007http://www.cnpq.br/documents/10157/ae2e400a-ab13-4411-acdf-b21fd43b189) e, A Soberania da clínica na psicopatologia do citidiano - Org. - (Ed. Garamond, 2009), O Erotismo e o Paraíso (Ed. As Musas, 2010) e Culpa, Sacrifício e Supereu na Obra de Marta Gerez Ambertín - Org. - (Ed. As Musas, 2014). Cartilha Atenção Psicológica nas Delegacias (2017). Orienta monografias dissertações e teses. E-mail: henrique.carneiro@upe.br 
ORCID ID: https://orcid.org/0000-0002-1861-0793

Editor(a) Responsável: Leandro Costa

Pareceristas Ad Hoc: LENINA SILVA E ADRIANA APARECIDA DE SOUZA

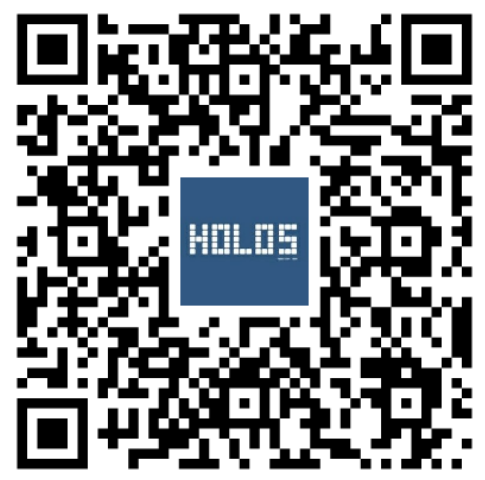

